\title{
DIKADOA (Una ópera para Philip Glass) ${ }^{1}$
}

\author{
de Alfonso Zurro ${ }^{2}$ \\ Dramaturgo, director de escena y profesor de dramaturgia.
}

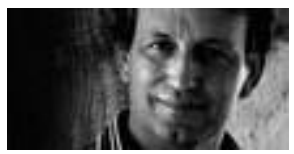

${ }^{1}$ Texto cedido para esta publicación por el autor. Ha sido escrita pensada para ser puesta en escena utilizando nuevas tecnologías teatrales y de la comunicación.

${ }^{2}$ Salamanca, 1953. Entre las más de treinta puestas en escena que ha dirigido, cabría mencionar: Mockinpott de Peter Weiss, La casa de Bernarda Alba de García Lorca, Esperando a Godot de Samuel Beckett, Pasodoble de Miguel Romero Esteo , Los borrachos de Antonio Álamo, Tartufo de Molière- Fernán Gómez ...

Como autor, de sus obras estrenadas, cabe destacar: Farsas Maravillosas, Bufonerías, Quién mal anda, A solas con Marilyn, El extraordinario vuelo de los ángeles. Algunas de ellas han sido traducidas, publicadas y representadas en francés, inglés, rumano, catalán..., así como en diversos países de Sudamérica. 
Obertura

la pantera negra atraviesa el escenario negro

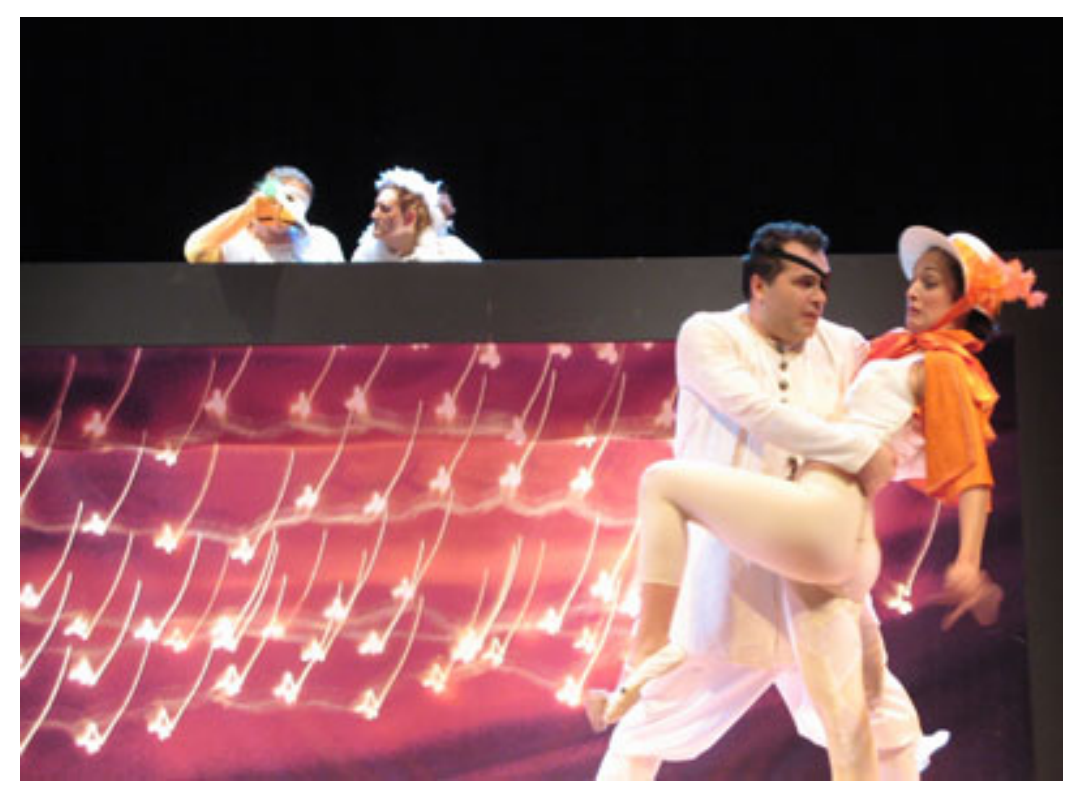

Imagen de la obra Bufonerías

Acto $1^{\circ}$

una higuera esquelética

su único fruto un niñito ahorcado

viento

el cuerpo se balancea

el ave del paraíso se posa sobre una rama de la higuera

aria de amor del ave

largo silencio

el ave se posa sobre el hombro del niño y picotea sus ojos

soldados desfilando

voz del general Queipo de Llano arengando al pueblo de Sevilla 
la pantera negra atraviesa el escenario negro

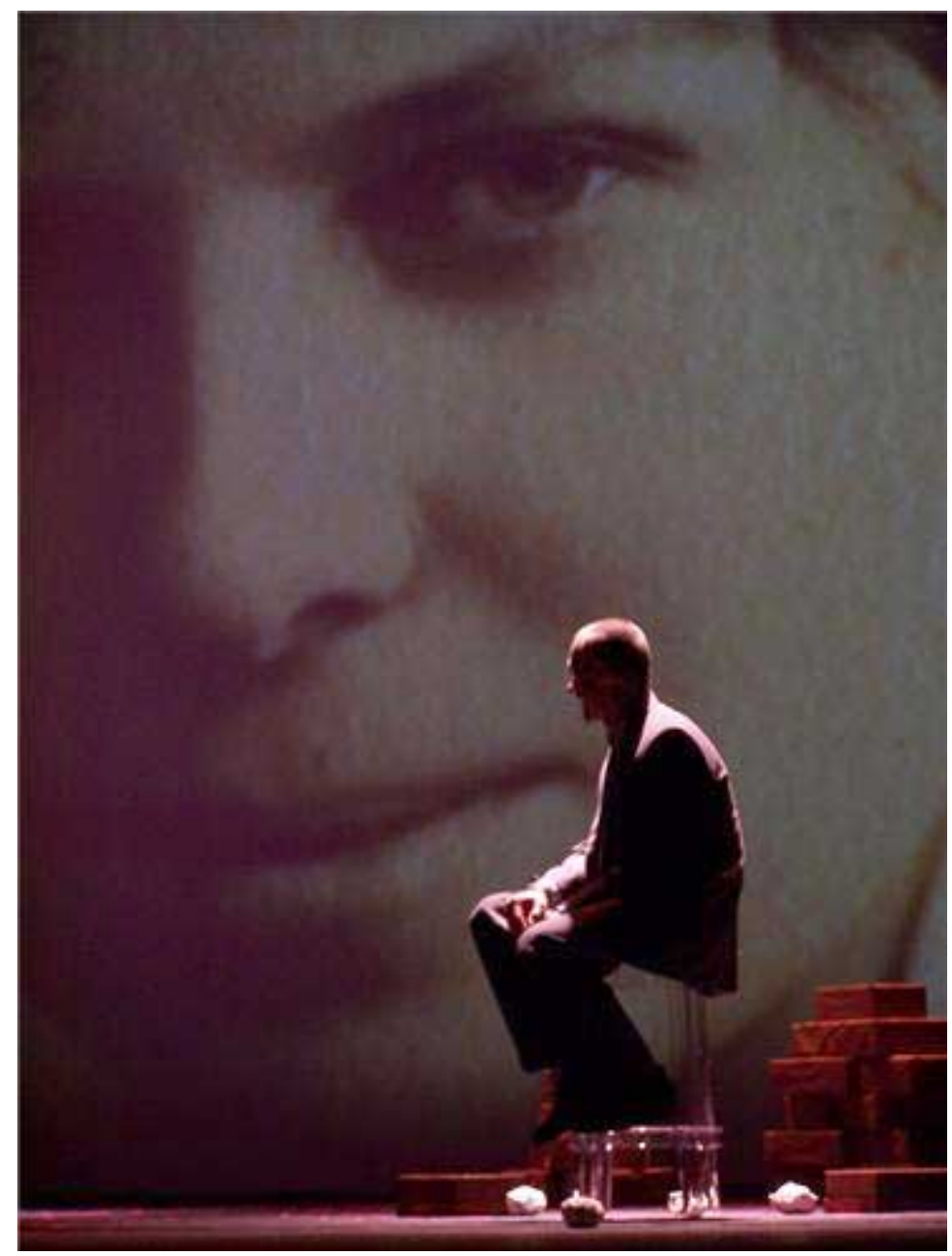

Imagen de la obra Me llamo Juan Ramón Jiménez

Acto $2^{\circ}$

doce naranjos alineados

Luís Cernuda arranca naranjas

nubes

nubes

doce pelotaris sudorosos 
Luís Cernuda arranca naranjas

la danza de los doce pasos de la danza de los doce pelotaris

de las nubes desciende una mujer con una tetera

los pelotaris toman te

llueve

los pelotaris se resguardan bajo los árboles

Luís Cernuda arranca naranjas

la pantera negra atraviesa el escenario negro

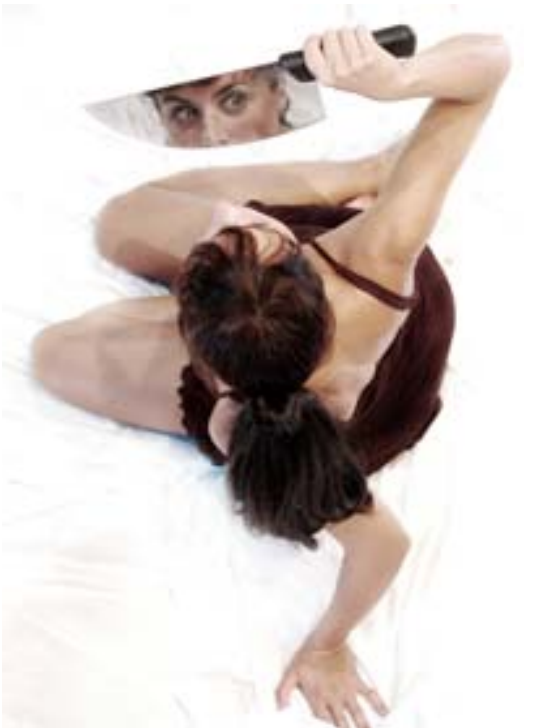

Imagen de la obra A solas con Marilyn

Acto $3^{\circ}$

despacho oficial estilo mudéjar con gran mesa en el centro

seis teléfonos y seis telefonistas a la derecha

seis teléfonos y seis telefonistas a la izquierda

llueve papelería oficial

los teléfonos atruenan 
de uno de los cajones de la mesa sale uno de los enanos del bombero torero

el enano besa los pies de las telefonistas

llueve papelería oficial

el gran hombre da vueltas alrededor de la mesa

el gran hombre saca de sus bolsillos dos tortugas y las coloca en un extremo de la mesa

el gran hombre espera en el otro extremo la llegada de las tortugas

llueve papelería oficial

la pantera negra atraviesa el escenario negro

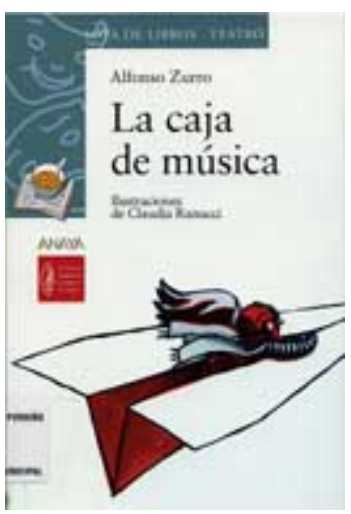

Portada del libro La caja de música

Acto $4^{\circ}$

arde la casita cortijera

los siete niños de Écija orinan sobre ella hasta apagarla

montes y colinas en lenta procesión inundan el escenario

falsa luna y falsas estrellas bailan en el firmamento

los niños apedrean la luna 
la luna se rompe

en el cielo los habitantes de disneylandia trazan sus carreras

un niño levanta la mano y muestra los cincos dedos

a un gesto el as de la baraja descomunal cae de las alturas a su mano

el as de oros gime largamente

al cielo vuelve la oscuridad

montes grises y colinas grises

arde la mano del niño

se incendia el as de oros

la pantera negra atraviesa el escenario negro

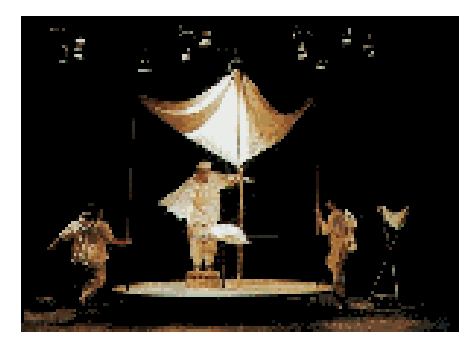

Imagen de Farsas maravillosas

Acto $5^{\circ}$

augusto abofetea a clown

la lona rayada en verde se abre

nueve hombres enchaquetados ante nueve micrófonos

coro de los corbatienses

augusto abofetea a clown

la trapacista corta el aire del escenario

el malabarista voltea ojos sin pestañas 
nueve leones y nueve látigos

augusto abofetea a clown

la trapecista pierde el equilibrio y cae lentamente

lentamente

el ángel de la guarda no llega a tiempo

augusto abofetea a clown

la pantera negra atraviesa el escenario negro

Acto $6^{\circ}$

a lo lejos la ciudad

rayos y bolas de fuego caen sobre ella

tres ancianos en bicicleta

ballet pavoroso de los ancianos que huyen

trece uniformes metálicos

el fuego sigue derramándose sobre la ciudad

los uniformes detienen a los ancianos

los uniformes flagelan a los ancianos

los uniformes torturan a los ancianos

coro de la alegría de las manos ensangrentadas

los uniformes fusilan a los ancianos

la ciudad arde

entre las llamas la Virgen Macarena huye hacia los cielos

la pantera negra atraviesa el escenario negro

fin 
